\title{
ANALISIS KUALITAS AIR SUNGAI SARIO KECAMATAN SARIO MANADO SULAWESI UTARA
}

\author{
Gorby Corneles Tarima ${ }^{1)}$, Jemmy Abidjulu', Harry S. J. Koleangan ${ }^{1)}$ \\ ${ }^{1)}$ Jurusan Kimia, FMIPA, Universitas Sam Ratulangi, Manado \\ e-mail:gorbytarima@gmail.com; jemmyabidjulu@gmail.com; harrykoleangan@gmail.com
}

\begin{abstract}
ABSTRAK
Penelitian ini dilakukan untuk menganalisis kualitas air sungai Sario berdasarkan sifat fisika dan kimia sesuai dengan PP No 82 Tahun 2001. Penelitian dilakukan di laboratorium Baristand Industri Manado pada bulan November 2015, dengan 4 sampel air yang diambil pada 4 titik dari hulu sampai hilir sungai Sario Kota Manado menggunakan 7 parameter yaitu kekeruhan, pH, nitat, nitrit, BOD, COD dan DO. Hasil penelitian ini menunjukkan bahwa kualitas air sungai Sario yang sesuai dengan ambang baku mutu air berdasarkan PP No. 82 Tahun 2001 hanyalah pada bagian hulu sampai tengah Sungai sebelum memasuki wilayah Kota Manado, sedangkan pada sekitaran hilir sungai Sario telah tercemar yang berhubungan dengan aktivitas masyarakat dengan diindikasikan berdasarkan konsentrasi BOD, COD dan DO yang buruk dan tidak sesuai dengan ambang baku mutu air berdasarkan PP No. 82/2001.
\end{abstract}

Kata kunci : Kualitas Air, Sungai Sario

\section{ANALYSIS OF RIVER WATER QUALITY SARIO DISTRICT MANADO NORTH SULAWESI}

\begin{abstract}
This study was conducted to analyze the Sario river water quality based on physical and chemical properties in accordance with PP No. 82 of 2001. The study was conducted in laboratory Baristand Industry Manado in November 2015, with four water samples taken at 4 points from upstream to downstream Sario City Manado using 7 parameters: turbidity, $\mathrm{pH}$, nitat, nitrite, BOD, COD and DO. The results of this study indicate that the water quality in accordance with the Sario river water quality standard threshold under PP No. 82 of 2001 only on the upstream side to the middle of the river before entering the city of Manado, whereas the downstream Area Sario river has been polluted related community activities to be indicated by the concentration of BOD, COD and DO poor and not in accordance with the water quality standard threshold based PP No. 82 of 2001.
\end{abstract}

Keywords: Water Quality, River Sario

\section{PENDAHULUAN \\ Latar belakang}

Air mempunyai peran yang sangat penting bagi kehidupan manusia. Selain untuk memenuhi kebutuhan sehari-hari seperti minum, memasak, mencuci, mandi dan sanitasi, air juga dibutuhkan dalam jumlah besar untuk kebutuhan dalam aktivitas ekonomi dan sosial. Sebagai contoh dalam industri, penggunaan air dapat dikategorikan menjadi beberapa kelompok yaitu air untuk keperluan umum, air proses, air pendingin, dan air umpan boiler.
Salah satu sumber air yang paling banyak berinteraksi dengan manusia adalah sungai. Beberapa contoh fungsi sungai adalah sumber air bagi petani, sebagai sarana transportasi, sebagai sumber air minum, pembangkit tenaga listrik, tempat olahraga, mencuci dan mandi. Disamping fungsi umumnya, sungai juga mempunyai peran penting dalam proses hidrologi dan merupakan sistem aquatik yang sangat dipengaruhi lingkungan sekitarnya.

Sungai Sario merupakan sungai utama dari DAS Sario dengan panjang aliran sungai $\pm 15 \mathrm{~km}$ dan merupakan sungai utama dari DAS Sario. Dari segi administratif DAS 
Sario mencakupi sebagian wilayah Kota Manado dan Kabupaten Minahasa. Kota manado merupakan hilir dari DAS Sario yang meliputi daerah Citraland, Wanea, Tanjung Batu, dan Sario.

Agustiningsih, et al. (2012) mengungkapkan bahwa sungai adalah ekosistem yang mengalami pencemaran yang paling berat oleh karena semua pembuangan dari segala kegiatan baik dari perumahan, industri, semuanya berakhir di sungai yang mempengaruhi kualitas serta manfaat dan fungsi sungai itu sendiri. DAS Sario sendiri diapit oleh beberapa desa dan kecamatan yang mempunyai aktivitas penggunaan lahan seperti pemukiman pertanian dan industri yang diduga mempengaruhi kualitas air sungai Sario. Aktivitas pertanian dengan menggunakan pupuk dan pestisida dapat mempengaruhi kualitas air sungai melalui buangan dari lahan pertanian yang masuk kebadan air. Menurut Ruchirawat dan Shank (1996) bahwa pada proses penyemprotan lahan pertanian, sekitar 3-30\% dari bahan aktif pestisida mencapai target yang dituju, sedangkan sisanya sekitar $70 \%$ akan terbuang bersama aliran sungai sehingga berpeluang mengakibatkan pencemaran air di perairan. Menurut Priyambada, et al. (2008) bahwa perubahan penggunaan lahan yang ditandai dengan bertambahnya aktivitas domestik, pertanian dan industri akan memberikan dampak dan mempengaruhi kondisi kualiras air sungai terutama aktivitas domestik yang memberikan sumbangan BOD terbesar ke badan sungai. Pemerintah sendiri telah menetapkan melalui Peraturan Pemerintah No. 82/2001 tentang standart beban pencemaran dari kontaminan-kontaminan yang mempengaruhi kualitas air sungai. Berdasarkan hal-hal tersebut, maka perlu dilakukan analisis kualitas air sungai Sario, serta mengetahui sejauh mana kriteria air sungai tersebut sesuai yang ditetapkan oleh pemerintah.

\section{METODOLOGI PENELITIAN Lokasi Penelitian}

Penelitian ini akan dilakukan di laboratorium Baristand Industri Manado pada bulan November 2015. Sampel air diambil dibeberapa titik dari hulu sampai hilir sungai Sario. Dimana beberapa titik mewakili daerah yang diduga mengandung kontaminan- kontaminan hasil dari aktivitas pertanian dan peternakan ataupun limbah hasil aktivitas rumah tangga yang mempengaruhi kualitas air sungai Sario.

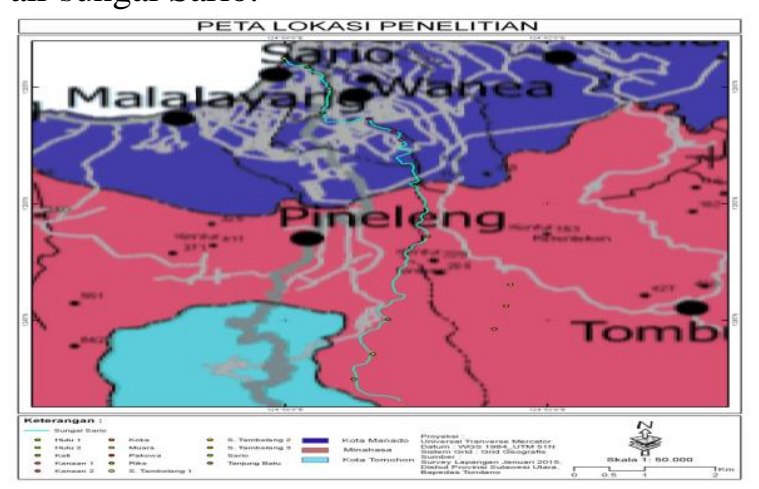

Gambar 1. Peta sungai Sario

1. Titik $1\left(124^{\circ} 50^{\prime} 31,9^{\prime \prime} \mathrm{E}, 1^{\circ} 22^{\prime} 59,2^{\prime \prime} \mathrm{N}\right){ }^{\prime}$ berlokasi di hulu sungai Sario disekitar kaki gunung mahawu.Titik ini teridiri dari hutan.

2. Titik $2\left(124^{\circ} 51^{\prime} 5,2^{\prime \prime} \mathrm{E}, 1^{\circ} 25^{\prime} 26,2^{\prime \prime} \mathrm{N}\right)$ berlokasi di Desa Kali meawakili area yang mempunyai lahan pertanian dan peternakan.

3. Titik $3\left(124^{\circ} 50^{\prime} 19,0^{\prime \prime} \mathrm{E}, 1^{\circ} 28^{\prime} 1,9^{\prime \prime} \mathrm{N}\right)$ berlokasi di Sario kota Manado mewakili daerah yang mempunyai aktivitas industri.

4. Titik $4\left(124^{\circ} 50^{\prime} 11,0^{\prime \prime} \mathrm{E}, 1^{\circ} 28^{\prime} 11,0^{\prime \prime} \mathrm{N}\right)$ berlokasi di Tanjung Batu yang merupakan hilir dari sungai Sario.

\section{Alat dan Bahan}

Dalam penelitian ini, alat yang digunakan adalah alat yang biasa digunakan dalam menguji kualitas air. Alat-alat yang digunakan antara lain botol PEP 1L, keeping socchi, stop watch, gabus, termometer $\mathrm{Hg}$, cool box, botol winkler, dan Spektroskopi Uv-Vis.

Bahan-bahan yang digunakan dalam penelitian ini adalah sampel air sungai Sario, aquades, larutan aquades asam nitrat, asam askorbat, larutan indicator dikromat 5\%, larutan $\mathrm{AgNO}_{3}$.

\section{Analisis Data}

Data yang diperlukan terdiri data primer dan data sekunder. Data primer meliputi data kualitas air Sungai Sario baik parameter fisika dan kimia yaitu kekeruhan, pH, BOD, COD, DO, Nitrat, Nitrit. Data primer didapatkan dengan melakukan pengamatan dan pengambilan sampel secara 
langsung kemudian dilanjutkan dengan analisis di laboratorium. Data sekunder diperoleh dari dinas/intansi terkait. Analisis kualitas air dengan mengacu baku mutu kualitas air sungai menurut PP 82/2001.

\section{Prosedur Kerja} Kekeruhan

Sampel dihomogenkan dengan cara dikocok kemudian dimasukan dalam kuvet. Kuvet yang berisi sampel dianalisa dengan alat turbidimeter dan dibaca nilainya.

\section{Penetuan pH}

Kedalam gelas piala $150 \mathrm{~mL}$ dimasukkan $100 \mathrm{~mL}$ sampel kemudian dicelupkan elektroda dari pH-meter, dan dibaca nilai $\mathrm{pH}$ pada alat.

\section{Penentuan Nitrat}

Penentuan nitrat dilakukan dengan metode reduksi kadmium. Dibuat deret standard larutan pembanding yang diketahui nilai konsentrasinya dan kedalam botol sampel dimasukkan $25 \mathrm{~mL}$ sampel air kemudian di tambahkan reagen NitraVer 5 Nitrate lalu dikocok selama 1 menit dan didiamkan selama 5 menit, kemudian dianalisis menggunakkan spektrofotometer $U v$-Vis pada panjang gelombang $500 \mathrm{~nm}$. Mula-mula dimasukkan botol blanko dan bacaan pada alat dan alat diset pada angka nol. Selanjutnya botol blanko digantikan dengan botol deret standard kemudian dilanjutkan dengan botol sampel dan konsentrasi nitrat dalam $\mathrm{mg} / \mathrm{L}$ ditunjukkan langsung pada alat.

\section{Penentuan DO}

1. Dipipet $2 \mathrm{ml}$ larutan mangan sulfat kedalam sampel yang ada dalam botol winkler dimana penambahan dilakukan di bawah permukaan cairan.

2. Ditambah $2 \mathrm{ml}$ larutan alkali-iodidaazida kemudian botol ditutup kembali untuk mencegah udara terperangkap udara luar, kemudian dikocok dengan membalik-balikkan botol beberapa kali.

3. Dibiarkan 10 menit agar gumpalan mengendap. Setelah pengendapan sempurna, maka bagian larutan yang jernih dikeluarkan dari botol dengan menggunakan pipet ; sebanyak kurang lebih $100 \mathrm{ml}$ dipindahkan dalam Erlenmeyer $500 \mathrm{ml}$.

4. Ditambahkan $2 \quad \mathrm{ml}$ $\mathrm{H}_{2} \mathrm{SO}_{4}$ pekat dikocok, dimasukkan kedalam Erlenmeyer $250 \mathrm{ml}$

5. Dititrasi dengan larutan tiosulfat $0,025 \mathrm{~N}$ sampai timbul warna kuning pucat.

6. Ditambah indicator kanji 1- $2 \mathrm{ml}$ sehingga timbul warna biru. Titrasi dilanjutkan sampai warna biru hilang, dicatat volum titrasi dan volum contoh

\section{Pengujian COD}

1. Pipet $50 \mathrm{ml}$ larutan sampel ke dalam Erlenmeyer $250 \mathrm{ml}$

2. Tambahkan $5 \mathrm{ml} \mathrm{KMnO} 4$ ) $0.1 \mathrm{~N} /$ $\mathrm{K}_{2} \mathrm{Cr}_{2} \mathrm{O} 7$ dan panaskan selama satu jam dalam penangas air.

3. Didnginkan selama 10 menit, tambahkan larutan $\mathrm{KI} 10 \%$ dan $10 \mathrm{ml} \mathrm{H}_{2} \mathrm{SO} 46 \mathrm{M}$

4. Titrasi dengan larutan thiosulfat $0.05 \mathrm{~N}$ sampai warna kuning, tambah $1-2 \mathrm{ml}$ indicator kanji sampai timbul warna biru dan lanjutkan titrasi sampai warana biru hilang

5. Lakukan hal yang sama terhadap blanko

\section{Pengujian BOD}

1. Pipet $100 \mathrm{ml}$ sampel kedalam larutan Erlenmeyer tutup asah, tambahkan $1 \mathrm{ml}$ MnSO4 dan $1 \mathrm{ml}$ larutan alkali azida.

2. Tutup sampel dan kocok dengan membolak- balikkan botol beberapa kali

3. Biarkan hingga terbentuk endapan setengah bagian

4. Buka tutup sampel dan panaskan dalam $\mathrm{H}_{2} \mathrm{SO} 4$ pekat melalui dinding botol,kemudian tutup botol kembali

5. Kocok kembali sampai endapan melarut

6. Titrasi larutan dengan natrium thiosulfat $0.1 \mathrm{~N}$ sampai berwarna kuning muda, tambahkan 1-2 ml indicator kanji sampai warna biru dan lanjutkan titrasi sampai warna biru hilang.

\section{Penentuan Nitrit}

Penentuan nitrit dilakukan dengan metode ferrosulfat.Pada botol sampel dimasukan $10 \mathrm{~mL}$ sampel air kemudian ditambahkan reagen NitriVer 2 Nitrite lalu 
dikocok sampai larut dan didiamkan selama 10 menit.Pada botol blanko dimasukkan 10 $\mathrm{mL}$ sampel.Konsentrasi nitrit dianalisis dengan spektrofotometer Uv-Vis pada panjang gelombang $585 \mathrm{~nm}$. Mula-mula dimasukkan botol blanko kemudian diset pada nilai nol dan larutan deret standar serta larutan sampel, kemudian konsentrasi nitrit dalam $\mathrm{mg} / \mathrm{L}$ ditunjukkan langsung pada alat.

\section{HASIL DAN PEMBAHASAN Hasil}

Data hasil analisis kualitas air sungai Sario dilakukan di empat titik lokasi pengambilan menggunakan 7 parameter yaitu kekeruhan, $\mathrm{pH}$, nitat, nitrit, $\mathrm{BOD}, \mathrm{COD}$ dan DO. Baku mutu yang digunakan mengacu pada kriteria mutu air sesuai kelas air pada Peraturan Pemerintah Nomor 82 Tahun 2001 tentang Pengolahan Kualitas Air dan Pengendalian Pencemaran Air. Hasil analisis sampel disajikan pada tabel sebagai berikut :

Tabel 1. Hasil analisis kualitas Sungai Sario

\begin{tabular}{|c|c|c|c|c|c|c|c|c|c|}
\hline Parameter & Satuan & Lok & si Peng & mbilar & Sampel & $\mathrm{Bal}$ & Mut & Air, $\mathrm{K}$ & las \\
\hline & & T1 & $\mathrm{T} 2$ & T3 & $\mathrm{T} 4$ & $\mathrm{I}$ & II & III & IV \\
\hline Kekeruhan & NTU & 1.1 & 3.9 & 5.6 & 12.7 & 0.5 & 0.5 & 0.5 & 0.5 \\
\hline $\mathrm{pH}$ & - & 7.92 & 7.73 & 7.66 & 7.17 & $6-9$ & $6-9$ & $6-9$ & $6-9$ \\
\hline Nitrat & $\mathrm{mg} / \mathrm{L}$ & 0.968 & 0.89 & 0.927 & 0.134 & 10 & 10 & 20 & 20 \\
\hline Nitrit & $\mathrm{mg} / \mathrm{L}$ & 0.002 & 0.005 & 0.061 & 0.05 & 0.06 & 0.06 & 0.06 & $(-)$ \\
\hline BOD & $\mathrm{mg} / \mathrm{L}$ & $<2$ & $<2$ & $<2$ & 15 & 2 & 3 & 6 & 12 \\
\hline COD & $\mathrm{mg} / \mathrm{L}$ & $<10$ & $<10$ & $<10$ & 68 & 10 & 25 & 50 & 100 \\
\hline $\mathrm{DO}$ & $\mathrm{mg} / \mathrm{L}$ & 7.4 & 7.42 & 7.01 & 1.99 & 6 & 4 & 3 & 0 \\
\hline
\end{tabular}

Sumber : Data primer (2015), Baku mutu air mengacu PP Nomor 82 Tahun 2001

\section{Pembahasan}

Kekeruhan air sungai dipengaruhi oleh materi-materi yang tersuspensi di dalam air sungai yang pada umumnya dibawah oleh aliran permukaan saat hujan turun. Nilai kekeruhan dari titik pertama (T1) sampai pada titik keempat (T4) semakin meningkat dan tidak sesuai dengan baku mutu air yang telah ditetapkan. Ini mengindikasikan bahwa sungai Sario memiliki tingkat kekeruhan air yang buruk dan tidak sesuai untuk peruntukan kelas I sampai kelas IV baik dari hulu maupun ke hilir.

Berdasarkan baku mutu air, $\mathrm{pH}$ air yang baik berkisar 6-9. Sebagian besar organisme aquatik peka terhadap perubahan $\mathrm{pH}$ namun lebih menyukai $\mathrm{pH}$ mendekati pH netral (Novotny dan Olem, 1994). Sungai Sario memiliki nilai $\mathrm{pH}$ yang baik dan sesuai untuk peruntukan kelas I-IV yang berada pada kisaran 7-8 atau mendekati $\mathrm{pH}$ netral.

Senyawa nitrogen ditemukan baik di dalam air permukaan maupun air tanah.
Senyawa tersebut dapat berasal dari kegiatan pertanian (pupuk) atau pembuangan kotoran hewan atau manusia (Suprihatin dan Suparno, 2013). Hasil analisis nitrat dan nitrit sungai Sario memiliki nilai yang tidak melewati baku mutu air yang ditetapkan. Ini berarti penggunaan lahan sebagai pertanian ataupun peternakan tidak mempengaruhi kualitas air Sungai Sario.

BOD dan COD menunjukan jumlah oksigen terlarut yang dibutuhkan mikroorganisme dan bahan oksidan untuk mengoksidasi bahan-bahan organik yang terbuang kedalam sungai. Nilai BOD dan COD air sungai dapat menunjukan banyaknya pencemar organik yang ada di dalam air sungai (Novotny dan Olem 1994). BOD dan COD dari sungai Sario terpantau baik dari titik pertama (T1) hingga titik ketiga (T3). Namun pada titik keempat (T4), hasil analisis menunjukan konsentrasi BOD dan COD yang buruk karena melewati baku mutu air yang telah ditetapkan. Dengan kata lain, pada titik keempat (T4) sungai Sario mempunyai pencemar organik yang lebih 
banyak dibandingkan titik pertama sampai titik ketiga (T4).

Begitu juga dengan konsentrasi DO atau oksigen terlarut, semakin tinggi konsentrasi oksigen terlarut maka tingkat pencemaran akan semakin berkurang. Sebaliknya, semakin rendah konsentrasi oksigen terlarut mengindikasikan kualitas air yang buruk. Konsentrasi DO terendah terdapat pada titik keempat (T4) pengambilan sampel dan tidak sesuai dengan baku mutu yang telah ditetapkan. Berhubungan dengan konsentrasi BOD dan COD sungai Sario pada titik ini, maka dapat diketahui konsumsi oksigen yang tinggi baik dari mikroorganisme maupun bahan oksidan dalam mengoksidasi bahan organik ataupun anorganik pada titik ini, sehingga konsentrasi oksigen terlarut semakin berkurang dan mengurangi kualitas air sungai Sario.

\section{KESIMPULAN DAN SARAN Kesimpulan}

Berdasarkan hasil penelitian maka dapat disimpulkan bahwa kualitas air sungai Sario yang sesuai dengan ambang baku mutu air berdasarkan PP No. 82/2001 hanyalah pada bagian hulu sampai tengah Sungai sebelum memasuki wilayah Kota Manado, sedangkan pada sekitaran hilir sungai Sario telah tercemar yang berhubungan dengan aktivitas masyarakat dengan diindikasikan berdasarkan konsentrasi BOD, COD dan DO yang buruk dan tidak sesuai dengan ambang baku mutu air berdasarkan PP No. 82/2001.

\section{Saran}

Perlu dilakukan analisis yang lebih lanjut tentang kontaminan-kontaminan anorganik terhadap bagian hilir sungai Sario, karena berdasarkan analisis BOD, COD dan DO dapat diperkiran pada bagian hilir sungai Sario terdapat bahan buangan anorganik yang berbahaya karena konsumsi oksigen yang tinggi pada bagian hilir sungai sario.

\section{DAFTAR PUSTAKA}

Achmad, R. 2004. Kimia Lingkungan. Andi, Yogyakarta.

Addy, K., L. Green, dan E. Herron. 2004. $p H$ and Alkalinity. Di dalam: URI
Watershed Watch. Cooperative Extension of the Environment and Life Science; Rhode Island. 3 Juli 2004. University of Rhode Island. Hlm 1-4.

Agustiningsih, D., S. B. Sasongko, dan Sudarno. 2012. Analisis Kualitas Air dan Strategi Pengendalian Pencemaran Air Sungai Blukar Kabupaten Kendal. Di dalam: Pengelolaan Sumber Daya Alam dan Lingkungan. Prosiding Seminar Nasional; Semarang, 11 September 2012. Universitas Dipenogoro. Hlm 30-37.

Http://sda.jatimprov.go.id/uploads/berkas/La mpiran\%20PP\%20No.\%2082\%20Ta hun\%202001.pdf [30 Januari 2016] Peraturan Pemerintah Nomor 82 Tahun 2001 Tentang Pengelolaan Kualitas Air dan Pengendalian Pencemaran Air.

Liptak G. B. 1994. Analytical Instrumentation,Chilton Book Company, Pensylvania.

Novotny, V., dan H. Olem. 1994. Water quality: Prevention, Identification, and Management of Difusse Pollution. New York: van Nostrand Reinhold.

Priyambada, I. B., W. Oktiawan, dan R. P. E. Suprapto. 2008. Analisa Pengaruh Perbedaan Fungsi Tata Guna Lahan terhadap Beban Cemaran BOD Sungai (Studi Kasus Sungai Serayu Jawa Tengah). Jurnal Presipitasi. 5(2): $55-62$

Ruchirawat, M., dan C. R. Shank. 1996. Enviromental Toxicology International Center for enviromental and Industrial Toxicologi (ICEIT). Chulabhorn Research Institute, Bangkok.

Suprihatin dan Suparno O. 2013. Teknologi Proses dan Pengolahan Air. IPB Press, Bogor.

Srinivas, T. 2008. Environmental Biotechnology. New Age, Visakhapatnam. 